\title{
LOW-COST RUBBER COMPOUNDS FOR FIBER-REINFORCED ELASTOMERIC ISOLATORS: RECOVERED POWDERS AND WASTE OILS FROM RUBBER MANUFACTURING PROCESSES
}

\author{
Gaetano Pianese $^{1}$, Gabriele Milani ${ }^{1}$, Federico Milani ${ }^{2}$, Ahmad Basshofi Habieb ${ }^{3}$ \\ ${ }^{1}$ Politecnico di Milano \\ Piazza Leonardo da Vinci 32, 20133 Milano, Italy \\ e-mail: gaetano.pianese@polimi.it, gabriele.milani@polimi.it \\ ${ }^{2}$ Chem.Co. Consultant \\ Via Kennedy 2, 45030 Occhiobello, Rovigo, Italy \\ federico-milani@libero.it \\ ${ }^{3}$ Institut Teknologi Sepuluh Nopember \\ Keputih, Sukolilo, Surabaya City, East Java 60117, Indonesia \\ ahmad.basshofi@its.ac.id
}

\begin{abstract}
In recent years the concept of recycling and reuse is a popular issue faced in many fields. During manufacturing processes a huge amount of materials is recovered to minimize waste. In particular, this study investigates the possibility of reuse materials recovered during the production of rubber in standard industrial practice, for the realization of low-cost rubber compounds for fiber-reinforced elastomeric isolators. To cope with this task, a new composition is developed basing on the past experience of the research group and in particular with reference to a previous study by A. B. Habieb et al, where a part of virgin rubber was replaced by regenerated one. Subsequently, a comparison between the two compositions in terms of rheometer curves, uniaxial tensile curves, hardness and compression sets, before and after the process of aging is provided. It is found that the new composition exhibits attractive performances with economic advantages and environmental benefits.
\end{abstract}

Keywords: Rubber compounds, Regenerated rubber, Elastomeric isolator. 


\section{INTRODUCTION}

The rubber material is widely used either for household or industrial needs. Since the prehistoric era, rubber has been involved in human life by exploiting the latex from specific trees. The first use of rubber in the industrial sector occurred at the beginning of the 18th century [1]. Nowadays, rubber is commonly used for tires, vibration or seismic isolators, impermeable layers, and sports equipment. It can be in the natural or synthetic form of material. Some popular synthetic rubber types include Hypalon, Ethylene Propylene Diene Monomer (EPDM), NitrileButadiene Rubber (NBR), Viton, Neoprene, Silicone rubber (SiR), and Styrene-Butadiene Rubber (SBR).

For elastomeric isolators, rubber pads have a main role. Damping performance is a prerequisite for isolation bearing materials. Besides, the materials must have an excellent overall performance, such as high strength to resist damage $[2,3]$. Natural Rubber (NR) exhibits desirable physical and mechanical properties, good processing properties, and excellent flexibility, and it is an indispensable material for industrial applications. However, NR has a quite poor damping performance, which greatly limits its application in the field of anti-seismic materials [4] [5]. Artificial rubber seems promising for the fabrication of isolators since NR is vulnerable to quick aging and its industrial production capability is limited. Less frequently it is EPDM or an NBR-EPDM blend vulcanized with an increasing amount in weight of carbon black [6].

To be ready for application, rubber should be processed through several stages; mixing or milling, and vulcanization $[7,8]$. In the mixing process, some additives are added to obtain the expected behavior of the rubber compound. In the vulcanization process, the rubber is heated with sulfur, accelerator, and activator at around $140-160{ }^{\circ} \mathrm{C}$. The process triggers the formation of cross-links between long rubber molecules, thus improving tensile strength, hardness, and weather resistance.

Rubber waste recycling is one of the most critical emergencies in terms of sustainability, considering that massive rubber waste has polluted the environment. According to the literature, regenerative rubber and powdered rubber are important forms of recycled rubber used to combat the rubber industry's expanding demand for raw material. Studies proposed by A. B. Habieb et al. $[9,10,11]$ validate the possibility of use regenerated EPDM compounds for the production of unbonded Fiber Reinforced Elastomeric Isolators. The utilization of regenerated EPDM appears very interesting because the EPDM backbone is essentially the same as the starting material.

The present study investigates the possibility of using recovered powder and oils from rubber manufacturing to fabricate rubber pads for low-cost seismic isolation systems. A new composition is developed basing on the past experience of the re-search group and in particular with reference to a previous study by A. B. Habieb et al. [12, 13].

In addition to the environmental benefits, the research wants to reveal remarkable ones of using recycled rubber waste from industries to drop down the cost of the isolation system. Such a consideration is particularly essential when dealing with seismic protection in developing countries (Indonesia, The Philippines, Thailand, for instance) where the cost of the commercial isolation system is considered too expensive for massive applications.

\section{REGENERATED EPDM COMPOUND}

The reference regenerated EPDM compound is the Batch 4 developed by A. B. Habieb et al. [14]. Commercial virgin rubber is blended with regenerated EPDM. Final rubber specimens are composed for $2 / 3$ of regenerated EPDM and $1 / 3$ of virgin rubber. In the following figures and tables are shown the mechanical properties of the recycled rubber. 


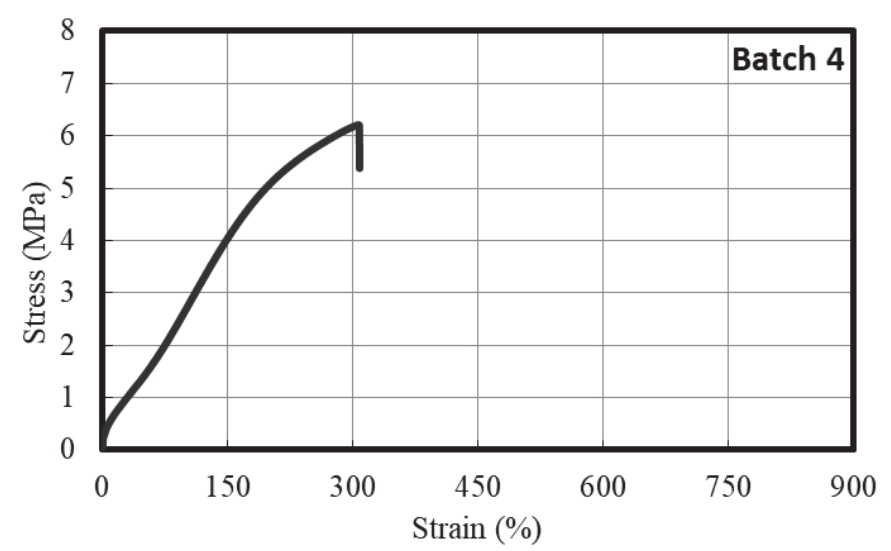

a)

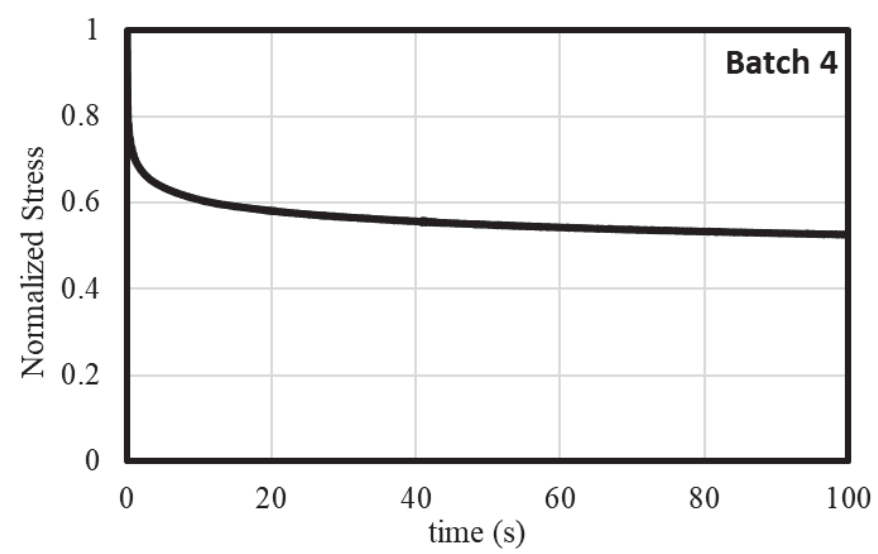

b)

Figure 1: Stretch-stress (a) and relaxation curves (b) of reactivated EPDM [9]

\begin{tabular}{llllllllll}
\hline $\begin{array}{l}\text { Time test } \\
\text { mm:ss }\end{array}$ & $\begin{array}{l}\mathrm{T} \\
{ }^{\circ} \mathrm{C}\end{array}$ & $\begin{array}{l}\mathrm{M}_{\mathrm{L}} \\
\text { kg-m }\end{array}$ & $\begin{array}{l}\mathrm{T}_{\mathrm{s} 1} \\
\text { mm:ss }\end{array}$ & $\mathrm{Ts} 2$ & $\mathrm{~T}_{10}$ & $\mathrm{~T}_{50}$ & $\mathrm{~T}_{90}$ & $\begin{array}{l}\mathrm{M}_{\mathrm{H}} \\
\text { kg-m }\end{array}$ & $\begin{array}{l}\text { Final } \\
\text { kg-m }\end{array}$ \\
\hline $36: 00$ & 150 & 0.062 & $1: 46$ & $2: 03$ & $2: 10$ & $7: 37$ & $1: 35$ & 0.352 & 0.352 \\
24:00 & 160 & 0.057 & $1: 16$ & $1: 27$ & $1: 32$ & $4: 56$ & $15: 55$ & 0.342 & 0.342 \\
$12: 00$ & 170 & 0.054 & $1: 05$ & $1: 13$ & $1: 17$ & $2: 34$ & $7: 25$ & 0.352 & 0.352 \\
6:00 & 180 & 0.052 & $0: 42$ & $0: 48$ & $0: 48$ & $1: 52$ & $4: 40$ & 0.272 & 0.272 \\
\hline
\end{tabular}

Table 1: Several parameters obtained in the rheometer test on specimens at different temperatures.

\begin{tabular}{lll}
\hline $\begin{array}{l}\text { Density } \\
\mathrm{g} / \mathrm{cm}^{3}\end{array}$ & $\begin{array}{l}\text { Shore A } \\
\text { Hardness }\end{array}$ & $\begin{array}{l}\text { Compression set } \\
\%\end{array}$ \\
\hline 1.089 & 66 & 25
\end{tabular}

Table 2: Density, Shore A Hardness and Compression Set of reactivated EPDM

\section{RUBBER COMPOUND WITH RECOVERED POWDERS AND OILS}

Respect the original composition of the rubber compound, carbon black and paraffinic oil have been totally replaced by recovered powders and oils (Table 3 ). Both replacements are obtained by recovering materials during the rubber manufacturing process, in particular, during the mixing process. In the following figures and tables are shown the mechanical properties of the new rubber compound. 


\begin{tabular}{|c|c|c|c|}
\hline $\begin{array}{l}\text { Batch } 4 \\
\text { Ingredient }\end{array}$ & gr. & $\begin{array}{l}\text { Recovered } \\
\text { Ingredient }\end{array}$ & gr. \\
\hline Virgin EPDM & 100.00 & Virgin EPDM & 100.00 \\
\hline Regenerated EPDM & 300.00 & Regenerated EPDM & 300.00 \\
\hline ZnO Zinc Oxide & 4.00 & ZnO Zinc Oxide & 4.00 \\
\hline Stearic acid & 1.00 & Stearic acid & 1.00 \\
\hline Calcium Carbonate & 40.00 & Calcium Carbonate & 40.00 \\
\hline Carbon black N550 FEF II & 185.00 & Recovered powder & 208.00 \\
\hline Paraffinic oil & 95.00 & Recovered oil & 88.00 \\
\hline - & - & Kezadol GR & 12.00 \\
\hline MBT Premix & 1.50 & MBT Premix & 1.52 \\
\hline Sulfur Premix & 2.50 & Sulfur Premix & 2.52 \\
\hline TMTD Premix & 2.00 & TMTD Premix & 2.00 \\
\hline Total & 731.00 & Total & 759.04 \\
\hline
\end{tabular}

Table 3: Composition for the two rubber compounds analyzed: "Batch 4" and "Recovered"

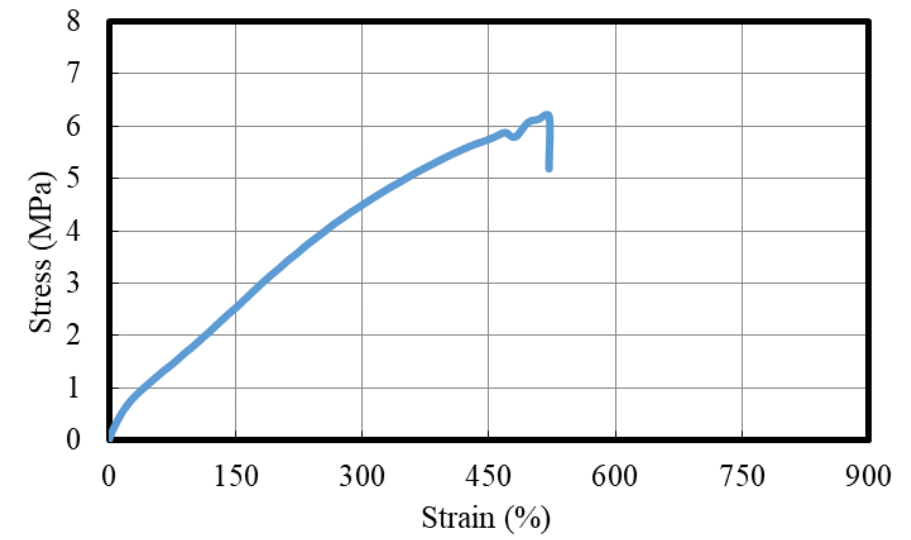

a)

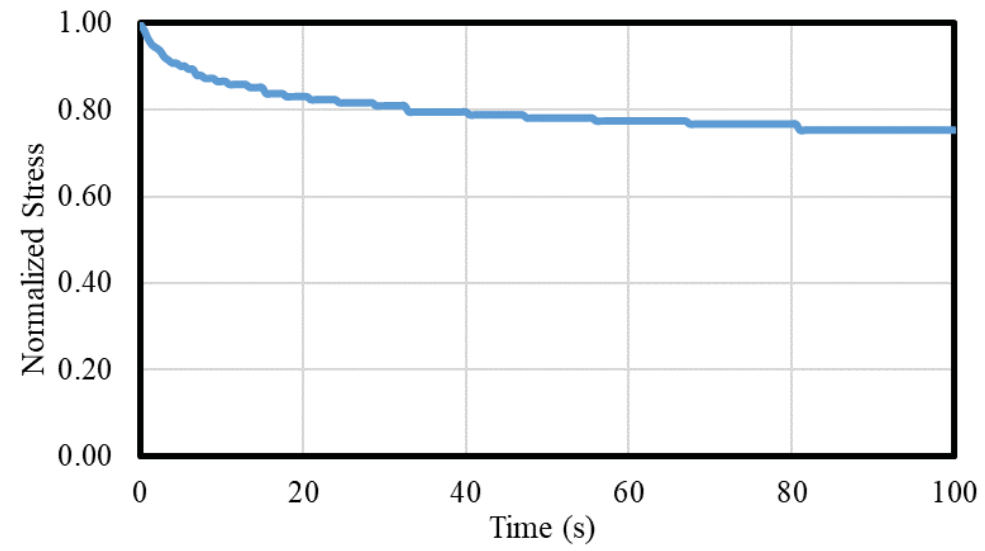

b)

Figure 3: Stretch-stress (a) and relaxation curves (b) of rubber compound with recovered powder and waste oil 


\begin{tabular}{llllllllll}
\hline $\begin{array}{l}\text { Time test } \\
\text { mm:ss }\end{array}$ & $\begin{array}{l}\mathrm{T} \\
{ }^{\circ} \mathrm{C}\end{array}$ & $\begin{array}{l}\mathrm{M}_{\mathrm{L}} \\
\mathrm{kg}-\mathrm{m}\end{array}$ & $\begin{array}{l}\mathrm{T}_{\mathrm{s} 1} \\
\mathrm{~mm}: \mathrm{ss}\end{array}$ & $\mathrm{Ts} 2$ & $\mathrm{~T}_{10}$ & $\mathrm{~T}_{50}$ & $\mathrm{~T}_{90}$ & $\begin{array}{l}\mathrm{M}_{\mathrm{H}} \\
\text { kg-m }\end{array}$ & $\begin{array}{l}\text { Final } \\
\text { kg-m }\end{array}$ \\
\hline $36: 00$ & 150 & 0.081 & $2: 50$ & $3: 22$ & $3: 25$ & $6: 46$ & $19: 47$ & 0.327 & 0.327 \\
$24: 00$ & 160 & 0.077 & $1: 52$ & $2: 09$ & $2: 11$ & $4: 16$ & $12: 20$ & 0,323 & 0.323 \\
$12: 00$ & 170 & 0.074 & $1: 15$ & $1: 26$ & $1: 26$ & $2: 39$ & $6: 51$ & 0.311 & 0.311 \\
$6: 00$ & 180 & 0.072 & $0: 53$ & $1: 00$ & $1: 00$ & $1: 45$ & $3: 52$ & 0.293 & 0.293 \\
\hline
\end{tabular}

Table 4: Several parameters obtained in the rheometer test on specimens at different temperatures.

\begin{tabular}{lll}
\hline $\begin{array}{l}\text { Density } \\
\mathrm{g} / \mathrm{cm}^{3}\end{array}$ & $\begin{array}{l}\text { Shore A } \\
\text { Hardness }\end{array}$ & $\begin{array}{l}\text { Compression set } \\
\%\end{array}$ \\
\hline 1.279 & 61 & 70.74
\end{tabular}

Table 5: Density, Shore A Hardness and Compression Set of reactivated EPDM

\section{COMPARISON BETWEEN THE RUBBER COMPOUNDS}

The new rubber compound exhibits similar behavior to the original one. In figure 3 and in tables 1 and 4, it's possible to appreciate the same characteristic rheometer curves (Table 1, Table 4).

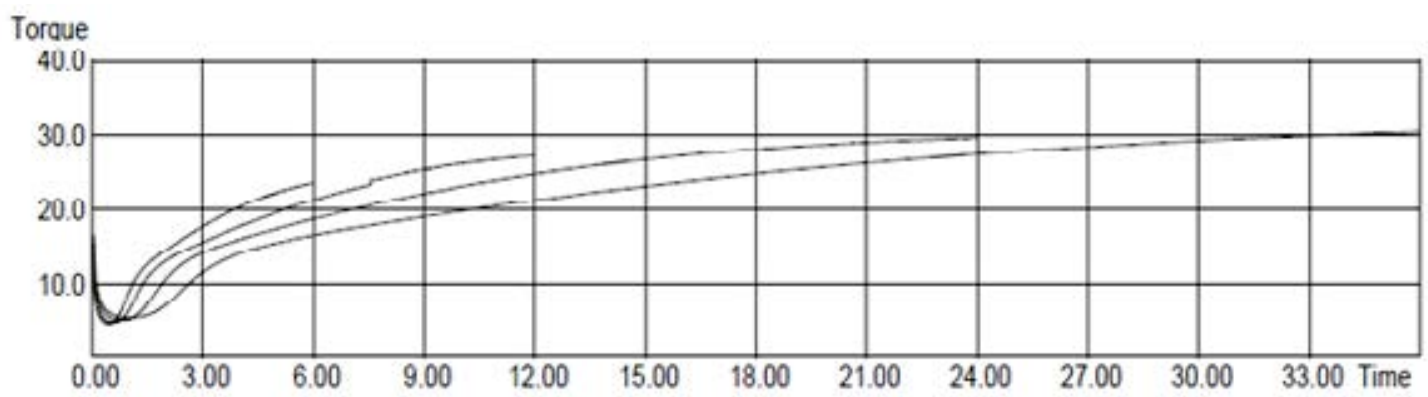

a)

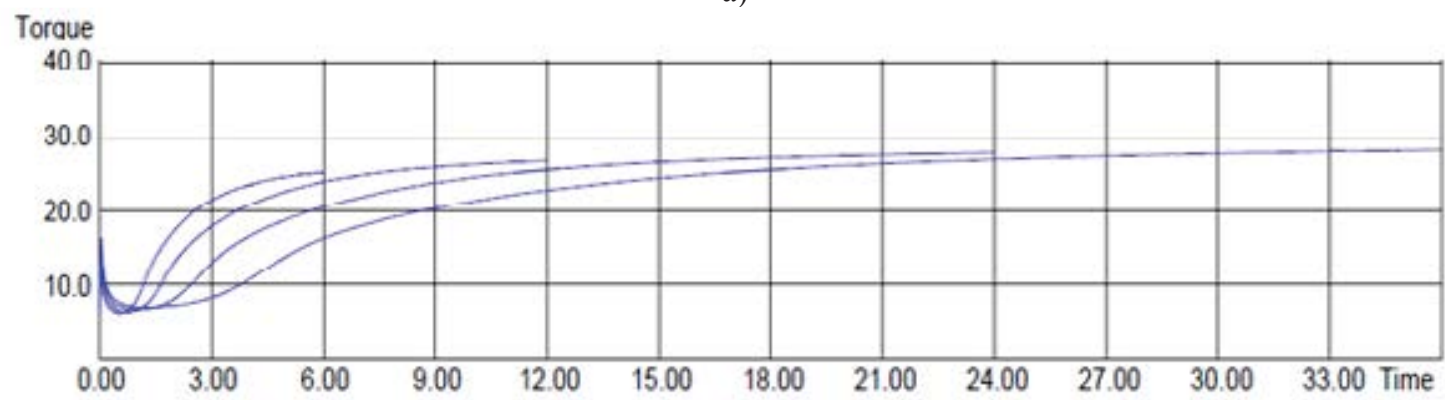

b)

Figure 3: Rheometer curves of "Batch 4" (a) and "Recovered" (b) at different temperatures

For the stretch-strain test, the results obtained have shown that the new rubber compound presents a higher elongation at break and almost the same breaking stress of the original composition (Figure 4a). For the relaxation curves, the original rubber compound reaches a plateau at a value of normalized stress, of 0.57 , while the new one reaches a plateau at a value of 0.79 .

Furthermore, a comparison of densities, Shore A Hardnesses and Compression Sets has been made. As it is possible to see in Table 6, only the compression set exhibits a different behavior, with a difference percentage of $177.04 \%$ lower than the original one. 


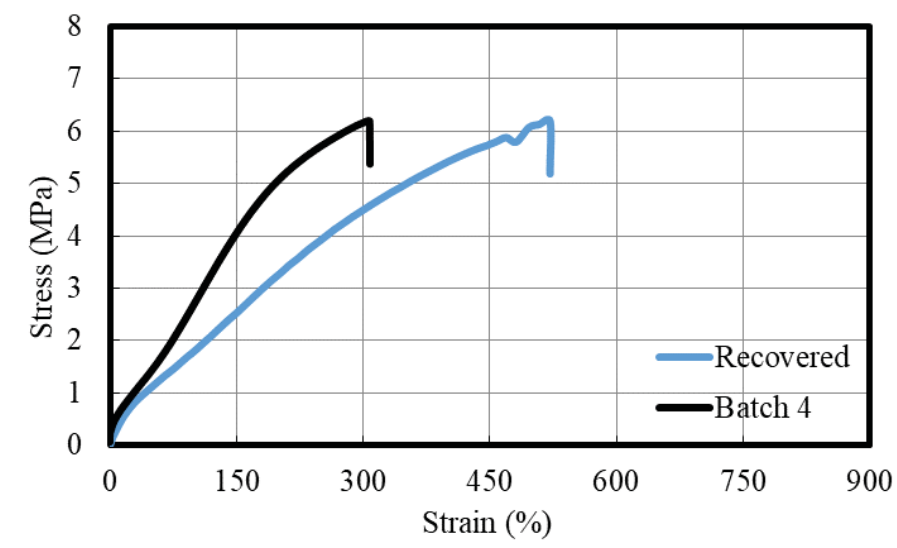

a)



b)

Figure 4: Comparison of stretch-stress (a) and relaxation curves (b) of the two rubber compounds

\begin{tabular}{llll}
\hline $\begin{array}{l}\text { Rubber } \\
\text { compound }\end{array}$ & $\begin{array}{l}\text { Density } \\
\mathrm{g} / \mathrm{cm}^{3}\end{array}$ & $\begin{array}{l}\text { Shore A } \\
\text { Hardness }\end{array}$ & $\begin{array}{l}\text { Compression set } \\
\%\end{array}$ \\
\hline Batch 4 & 1.089 & 66 & 25 \\
Recovered & 1.279 & 58 & 70.74 \\
$\Delta(\%)$ & 0.017 & 12.12 & 177.04 \\
\hline
\end{tabular}

Table 6: Comparison and percentage difference of densities, Shore A Hardnesses and Compression Sets

\section{CONCLUSIONS}

This paper has investigated the possibility of reuse materials recovered during the production of rubber in standard industrial practice to realize low-cost rubber compounds for fiberreinforced elastomeric isolators.

Firstly, from a previous study of A.B. Habieb et al., a rubber compound made of reactivated EPDM has been considered. From the original composition, carbon black and paraffinic oils have been totally replaced by recovered powder and oils. A comparison between the new rubber compound and the original one in terms of rheometer curves, uniaxial tensile curves, relaxation curves, hardness, and compression set has been done. The new rubber compound exhibits a good overall performance, except for the compression set. In fact, it has shown a percentage difference of $177.04 \%$ lower than the original one. 
So, for the production of rubber compounds for the low-cost elastomeric isolator, the recovered materials can't be used in total replacement of ingredients. Still, the results of rheometer curves, uniaxial tensile curves, relaxation curves, and hardness seem promising for future developments of this research where new compositions with partial replacements of recovered powder and waste oils will be proposed.

\section{REFERENCES}

[1] A. Coates, The commerce in rubber: the first 250 years. 2015.

[2] W. Wang, et al. Novel slide-ring material/natural rubber composites with high damping property. Scientific Report, Vol. 6, 22810/1-22810/13, 2016.

[3] Y-S. Choun, J. Park, I-K. Choi, Effects of mechanical property variability in lead rubber bearings on the response of seismic isolation system for different ground motions. Nuclear Engineering and Technology, Vol. 46, 605-618, 2014.

[4] R. Qin, R. Huang, X. Lu, Use of gradient laminating to prepare NR/ENR composites with excellent damping performance. Materials and Design. 2018, Vol. 149, 43-50.

[5] L. Burtscher S., A., Dorfmann, Compression and shear tests of anisotropic high damping rubber bearings. Engineerign Structures, Vol. 26, 1979-1991, 2004.

[6] G. Milani, F. Milani, Stretch-stress behavior of elastomeric seismic isolators with different rubber materials: numerical insight. Journal of engineering mechanics, Vol. 138(5), 416-429, 2012.

[7] C. Guise-Richardson, Redefining vulcanization: Charles goodyear, patents, and industrial control, 1834-1865. Technol Cult, 51:357-387, 2010.

[8] G. Pianese, G. Milani, R. Cerchiaro, F. Milani, Optimal Vulcanization of Unbonded Fiber Reinforced Elastomeric Isolator Devices, Chemical Engineering Transactions, Vol. 86, 2021.

[9] A. B. Habieb, G. Milani, V. Quaglini, F. Milani, Experimentation and numerical modelling of recycled rubber pads for seismic isolation under accelerated ageing. AIP Conference Proceedings, 2116, \# 420006, 2019.

[10] A. B. Habieb, G. Milani, T. Tavio, Two-step advanced numerical approach for the design of low-cost unbonded fiber reinforced elastomeric seismic isolation systems in new masonry buildings. Engineering Failure Analysis, 90, 380-396, 2018.

[11] A. B. Habieb, M. Valente, G. Milani, Base seismic isolation of a historical church using fiber reinforced elastomeric isolators. Soil Dynamics and Earthquake Engineering, Vol. 120, 127-145, 2019.

[12] A. B. Habieb, G. Milani, F. Milani, R. Cerchiaro, Rubber compounds made of reactivated EPDM for fiber-reinforced elastomeric isolators: an experimental study. Iranian Polymer Journal, 2020.

[13] A. B. Habieb, G. Milani, V. Quaglini, F. Milani, Experimentation and numerical modelling of recycled rubber pads for seismic isolation under accelerated ageing. AIP Conference Proceedings, 2116, \# 420006, 2019.

[14] A. B. Habieb, G. Milani, R. Cerchiaro, V. Quaglini, F. Milani, Numerical study on rubber compounds made of reactivated ethylene propylene diene monomer for fiber reinforced elastomeric isolators, Polymer Engineering and Science, 2020. 